\title{
Relationship between Organizational Culture, Emotional Intelligence and Job Satisfaction to Lecturers' Performance
}

\author{
Lambok Simamora ${ }^{1}$, Billy Tunas ${ }^{2}$, Widodo Sunaryo ${ }^{3}$ \\ Post Graduate Program, Universitas Pakuan Bogor, Indonesia
}

\begin{abstract}
The purpose of this research is to examine the effect of dependent variables of organizational culture, emotional intelligence, and job satisfaction with an independent variable, lecturers' performance when tested both individually or altogether. The survey is conducted by taking a sample of 84 lecturers of 4 (four) Theological Colleges by using proportional random sampling technique in Bogor and Bekasi West Java, Indonesia. The research used a Sequential Explanatory Design Mixed Method where quantitative research is conducted first then followed by the qualitative research. The study both quantitatively and qualitatively reveals that there is a positive significant relationship among variables under the following distribution of coefficient of correlation: organizational culture to lecturers' performance $=0.552$, emotional intelligence to lecturers' performance $=0.587$, job satisfaction to emotional intelligence $=0.609$ and when tested together it produces coefficient of correlation $=0.688$ and coefficient of determination $=0.473$ indicating the existence of other $52.7 \%$ variables not including in the model affecting lecturers' performance.
\end{abstract}

Keywords: organization culture, emotional intelligence, job satisfaction, performance, lecturers.

\section{INTRODUCTION}

Lecturers' performance is one important factors in the progress of a college. Lecturers' performance becomes very important as the performance degradation in both of individuals and groups within a university can give a significant impact. Thus, in this case a leader has a quite heavy task which he must always strive to improve performance and provide motivation for subordinates in order to improve performance to achieve the objective of the college. Educational institutions today both in private and public universities realize the importance of the human factor. Human resource has an important role in the utilization of resources within the organization. In this regard, to maximize the performance, lecturers must continuously strive to achieve the desired goals of the college. One objective of the colleges is to produce quality graduates that to achieve the goal then the college lecturers must have high performance. The college policy has a strong relationship to the performance of lecturers in college educational activities that the college must be able to set up the atmosphere in shaping the climate of good college resulting at high performance.

Based on the background and the results of the identification of the problem, the formulation of the problem is:

1. Does organizational culture positively affect lecturers's performance?

2. Does emotional intelligence positively affect lecturers's performance?

3. Does job satisfaction positively affect lecturers's performance?

4. Do organizational culture, emotional intelligence and job satisfaction altogether affect lecturers's performance?

\section{LITERATURE REVIEW}

According Rue and Byars (2007: 278), performance refers to the degree of completion of tasks that complement one's work. It reflects how well a person in carrying out the demands of a job. Basically, performance is determined by three factors: (a) effort, (b) ability, and (c) directions. In detail the three factors can be described as follows;

- Effort refers to how hard a person works.

- Ability is an effort that is related to one's ability

- Directions refers to how well the person understands what is expected of her work. 
Colquitt et al (2009: 37), suggests that performance is the value of a set of employee behaviors that contribute positively or negatively to achieve organizational goals. Basically performance has three dimensions, namely (a) task behavior, (b) moral behavior, and (c) rebelling behavior. Task behavior is the behavior of the employees who are directly involved in transforming the organizational resources in virtue, service or production organization. Moral behavior is activity in the form of employee volunteerism either with or without reward to contribute to the organization to improve overall quality in the workplace, e.g, ; working beyond formal duty, trying without expecting anything in return, loved the organization. Rebelling behavior is employees' behavior by deliberately blocking the achievement of objectives, e.g.; sabotage, theft, wastage of resources, corruption, sabotage, gossip, abuse, cruel treatment (torture).

Based on some opinions and understanding of theory described, it can be synthesized that performance in colleges is the performance of the academias who contributed, both quantity and quality, to the achievement of organizational objectives, with indicators of measurement: a. teaching plan, b. direction and goals, c. timeliness, d. working together, e. the quantity of work and $\mathrm{f}$. the quality of work.

Colquitt et al (2009: 546), define organizational culture as a social knowledge shared within an organization regarding the rules, norms, and values that shape the attitudes and behavior of employees. This definition helps highlight a number of aspects of the organization's culture. First, culture is a social knowledge among members of the organization. Employees learn about the most important aspect of culture through another employee. This knowledge transfer might be through explicit communication, simple observation, or by any other method. Moreover, a culture of sharing knowledge, which means that members of the organization understand and have a degree of consensus on what the culture is. According to Gibson, et al (2012: 31), organizational culture is how employees perceive and how these perceptions create a pattern of beliefs, values, and expectations. This definition indicates that culture involves ; (A) assumptions, (b) adaptation, (c) perception, and (d) learning. He further argued organizational culture consists of artifacts, creation, values, and basic assumptions. Artifacts and creation include: technology, art, and behavior patterns were seen and heard; The values include something that can be observed in the physical environment and something that can be tested only by the emerging social consensus, and t basic assumption includes the relationship with the environment, the reality of nature, time, space, natural life, activities of natural life, and the relationship between natural life.

According to Luthans (2012: 71), perhaps most closely associated with the study of organizational culture, definea it as the archetype of assumptions invented, discovered, or developed by certain groups such as learning to cope with external adaptation and internal integration that has worked quite well to be considered valuable and therefore, to be taught to new members as the correct way to perceive, think, and feel in relation to the matter.

Organizational cultures have a number of important characteristics. Some of the most readily agreed upon are as follows:

- Regularity observed behavior: when the participant organizations interact with each other, they use language, terminology, and the rituals associated with the respect and attitude.

- Norm: existing standards of conduct, including instructions on how much work needs to be done

- The dominant values: there are the core values that support organizations and expects the participants to share. Typical examples are products of high quality, low absenteeism, and high efficiency.

- Philosophy: policy, a set of beliefs about how the organization's employees and /or customers should be treated.

- Rules: there are strict guidelines associated with hanging out in the organization. Newcomers must learn them "the ties" to be accepted as a full member of the group.

- Organizational climate: this is a "feeling" total delivered by the physical layout, the participants how to interact, and members of the organization how to conduct themselves with the customer or other outside parties. 
Based on some opinions and understanding of the theory outlined above, it can be synthesized that organizational culture is a system of shared meaning adopted by the members of the organization that distinguishes these organizations and other organizations, with the indicators; a. innovation and risktaking, b. attention of detail, c. results-, d. people-orientated e.team-orientated , f. aggressiveness, and g. stability.

Zeidner, et.al, (2009: 25) argues that theories of emotional intelligence is divided into three ways as follows:

- Ability models, emotional intelligence as the ability, in which individuals who have high emotional intelligence will be superior to individuals who have low emotional intelligence in carrying out certain activities related to the emotions. There are four essential components of emotional intelligence, namely: identifying emotions, assimilating emotion in mind, understanding emotions, and managing the emotions of selves and others.

- Mixed models, an expanded conception and emotional intelligence includes the ability and qualities such as personality traits and motivations that can assist individuals in using emotional intelligence in real life. Individuals with sympathetic personality will be easier to use the skills to manage the emotions of other individuals. This mixed model includes quality, such as: optimism, empathy, and a good character.

- Trait emotional intelligence, is a comprehensive personality factors representing emotions, so individuals have personalities that are directly related to emotional functioning, such as selfconfidence, assertiveness, and empathy.

Covey (2005: 76) revealed that emotional intelligence is self-awareness, social sensitivity, empathy, and attempts to communicate well with others. Emotional intelligence is sensitivity about the right time, social decency and courage to admit weakness, to declare and to respect differences.

Stephen R. Covey explains that there are five main components of emotional intelligence that has been commonly accepted:

- Self-awareness is reflection of own life and to use this knowledge to improve and to overcome weakness. It is personal motivation related to what triggers a person's spirit, vision, values, goals, expectations, desires and passion to be a priority.

- Self-regulation is to manage oneself in order to achieve the vision and personal values.

- Empathy is understanding how others see and feel the things.

- Socialization and communication, which deals with how to resolve the differences, to solve problems, to generate creative solutions and to interact optimally to pursue common goals.

Covey further suggests that the best way to develop a systematic and five dimensions of EQ is through the seven habits of highly effective people , that is: be proactive, begin with the end goal, , think win-win, seek first to understand, then trying to understand, synergie and sharpening the saws.

Based on the theory, it can be synthesized that emotional intelligence is an individual personality characteristics embodied in the know, use, and manage the emotions of one self and others effectively in a productive social relationships to achieve organizational goals success.

The indicators to measure emotional intelligence, are : a) self awareness, b) emotional management), c) Self motivation, d) empathy e) social awareness.

The expert of organizational behavior, Ivancevich et al. (2006: 185), found: satisfaction is an attitude of the workers about their jobs resulted from the perception of them on job performed. Job satisfaction depends on intrinsic and extrinsic result and how the job holder perceived the results. These results have a different value for each person. For some people, the challenging work and responsible may have a neutral or even negative value because it depends on their education and experience in the past with regard to jobs that provide intrinsic results. For others, the results of such work may have positive value is high. The interests of each person gave to the work different. The differences will create different levels of job satisfaction in content that is essentially the same job. 
According Colquitt et al (2009: 105), job satisfaction is defined as an unpleasant emotional state resulting from the assessment of job or work experience. In other words, job satisfaction shows one's feelings about his work and what he thinks about the job. Employees with high job satisfaction will experience positive feelings when they think about their duties or take part in their work while employees with low job satisfaction will experience negative feelings when they think about their duties or take part in their work.

Based on some opinions and understanding of the theory outlined above, it can be synthesized that job satisfaction is the expression of individual attitudes toward work that reflects the pleasant and unpleasant experience by the fit between the expectations with reality gained from his work, with indicator a.Jobs , b , Supervision, c. Coworkers, d. Promotions, e. Acceptance of wages .

Based on above description, the following hypothesis is formulated:

1. Organizational culture positively affects lecturers's performance.

2. Emotional intelligence positively affects lecturers's performance.

3. Job satisfaction positively affects lecturers's performance.

4. Organizational culture, emotional intelligence and job satisfaction altogether affects lecturers's performance.

\section{Methodology}

This study applies Sequential Explanatory Design Mixed Method where quantiative study is ahead of qualitative study to examine the relationship between variables tested in the study using three independent variables through data obtained from questionnaires. The independent variable is Organizational Culture $\left(\mathrm{X}_{1}\right)$, Emotional Intelligence $\left(\mathrm{X}_{2}\right)$, and Job Satisfaction $\left(\mathrm{X}_{3}\right)$, while the dependent variable is the Lecturers's Performance $(\mathrm{Y})$.

The relationship among variables in the study described in Fig.1 below:

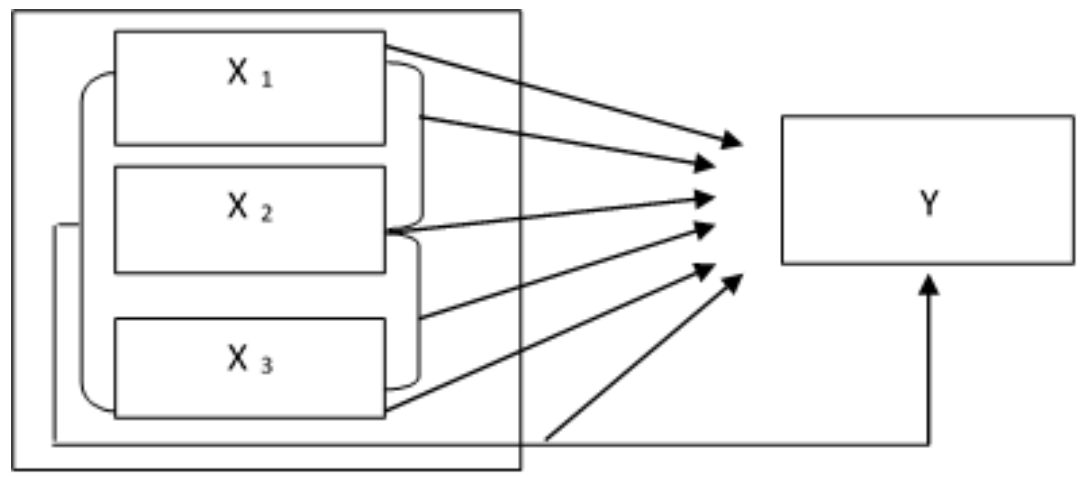

Figure1. Theoretical framework.

where,

$\mathrm{Y}=$ Lecturers's Performance

$\mathrm{X}_{1}=$ Organizational Culture

$\mathrm{X}_{2}=$ Emotional Intelligence

$\mathrm{X}_{3}=$ Job Satisfaction

The population of this study is 84 lecturers of Theological College out of 115 lecturers in the city of Bogor and Bekasi, West Java Indonesia. Hypothesis testing is conducted by using regression analysis to determine the influence of one or more independent variables on the dependent variable. The linearity assumption are prerequisites to proceed to further test. Hypothesis testing is performed at a significance level of 0.05 .

Qualitative study for the purpose of confirmation was performed through observation and interview to key informant as well as conducting focus group discussion. 


\section{RESUlT AND DISCUSSION}

The teachers of listed organisations were asked to participate in the survey by responding their opinions for four different measures in organizational culture, leadership, work satisfaction and performance. The linearity test is performed with $F$-test. Data is linear as the value of each variable is above the critical value for F-test.

\subsection{Organizational Culture and Lecturers's Performance}

In order to test whether data from organizational culture and lecturers's performance are linear, F-test has been conducted. Since the F value as shown in table 1 is higher than the critical value of $F$ table, we can proceed to test the alternate hypothesis if organizational culture is positively related to lecturers's performance within theological college in West Java, Indonesia. The strength of association of organizational culture $\left(\mathrm{X}_{1}\right)$ to lecturers's performance. $(\mathrm{Y})$ is observable from coefficient correlation $\left(r_{x 1}\right)=0.34$.

Tabel 1. Linearity test and coefficient of correlation of organizational culture $\left(X_{1}\right)$ to lecturers's performance $(Y)$

\begin{tabular}{|c|c|c|c|c|c|}
\hline Observation & $\mathbf{R}$ & $\mathbf{R}^{\mathbf{2}}$ & $\mathbf{F}_{\text {-test }}$ & $\mathbf{F}_{\text {- tabel }} \alpha$ & \multirow{2}{*}{ Conclusion } \\
\cline { 1 - 4 } $\mathbf{n}$ & $\mathbf{R x}_{\mathbf{1}}$ & $\mathrm{r}^{2} \mathrm{x}_{1}$ & $\mathbf{F x}_{\mathbf{1}}$ & 0.05 & \\
\hline 84 & 0.552 & 0.304 & 1.295 & 1.770 & Significant \\
\hline
\end{tabular}

$\mathrm{F}_{\text {test }}=1.295$ is below critical value where $\mathrm{F}_{\text {-tabel }}$ for $(\alpha=0.05)$ is 1.770 indicating that the data is linear and eligible for the next process. Coefficient of correlation $\left(\mathrm{r}_{\mathrm{x} 1}\right)=0.552$ indicates a medium positive relationship between organizational culture and lecturers's performance. Coefficient of determination $\left(\mathrm{r}^{2} \mathrm{x}_{1}\right)=0.304$ indicates that contribution of organizational culture to lecturers's performance is 30.4 $\%$.

This finding is in line with the theory put forward by Fred Luthans (2011), understanding organizational culture is a pattern of basic assumptions were discovered, invented or developed by a given group, with the intention that organizations learn to cope and tackling the problems that arise as a result of external adaptation and internal integration that has been running pretty well, so it needs to be taught to new members as the correct way to perceive, think and feel related with these problems.

Some of the results of previous studies have shown that organizational culture affects positively on the performance of lecturer, one of them is a study conducted by Eddy Surjadi Kramadibrata (2010) doing research on a sample of 1411 bank employees, indicate that there is a relationship positive significant relationship between organizational culture on performance, with a correlation coefficient $r$ $=0.619$.

\subsection{Emotional Intelligence and Lecturers's Performance}

To test whether data from emotional intelligence and lecturers's performance are linear, F-test has been conducted. The higher $\mathrm{F}$ value as shown in table 2 compared to the critical value of $\mathrm{F}$ table indicates the appropriateness of the model to test the alternate hypothesis if emotional intelligence is positively related to lecturers's performance within theological college in West Java, Indonesia. The strength of association of emotional intelligence $\left(\mathrm{X}_{2}\right)$ lecturers's performance $(\mathrm{Y})$ is observable from coefficient correlation $\left(\mathrm{rx}_{2}\right)=0.587$.

Tabel 2. Linearity test and coefficient of correlation of emotional intelligence $\left(X_{2}\right)$ to lecturers's performance $(Y)$

\begin{tabular}{|c|c|c|c|c|c|}
\hline Observation & $\mathbf{R}$ & $\mathbf{R}^{\mathbf{2}}$ & $\mathbf{F}_{\text {-test }}$ & $\mathbf{F}_{\text {- tabel }} \alpha$ & \multirow{2}{*}{ Conclusion } \\
\cline { 1 - 4 } $\mathbf{n}$ & $\mathbf{R} \mathbf{x}_{\mathbf{2}}$ & $\mathrm{r}^{2} \mathrm{x}_{2}$ & $\mathbf{F x}_{\mathbf{2}}$ & 0.05 & \\
\hline 84 & 0.587 & 0.345 & 1.255 & 1.770 & Linear \\
\hline
\end{tabular}

The table shows that $F_{\text {test }}=1.255$ is below the critical value where $F_{\text {-tabel }}$ for $(\alpha=0.05)$ is 1.770 indicating that the data is linear and eligible for the next process. Coefficient of correlation $\left(\mathrm{rx}_{2}\right)=$ 0.345 indicates a moderate positive relationship between emotional intelligence and lecturers's performance. Coefficient of determination $\left(\mathrm{r}^{2} \mathrm{x}_{2}\right)=0.345$ indicates that contribution of emotional intelligence to lecturers's performance is $34.5 \%$ while the rest $65.5 \%$ is determined by other factors not included in the model. 
This is consistent with the theory put forward by Stephen R. Covey (2005) stating that emotional intelligence is the knowledge of self, self-awareness, social sensitivity, empathy, and the ability to communicate well with others. Emotional intelligence is sensitivity about the right time, social decency and courage to admit weakness, declare and respect differences. This means that the higher the score of emotional intelligence, the higher score of lecturer performance. Thus, the results of this study further support the results of previous studies about the positive influence of emotional intelligence on lecturer's performance. Similarly, based on the analysis of the results of qualitative research through observation, interviews, focus group discussions and document review, it can be seen that there is a positive correlation with the emotional intelligence and lecturer's performance. This reinforces the results of quantitative research which proves significantly the second hypothesis of this study that there is a positive relationship between emotional intelligence and lecturer's performance where the regression equation is very significant and shows that any increase in emotional intelligence scores will improve lecturer's performance.

\subsection{Job Satisfaction and Lecturers' Performance}

Similar to previous model, to identify if data from job satisfaction and lecturers' performance are linear, F-test has been conducted. The higher F value as shown in table 3 compared to the critical value of $\mathrm{F}$ table indicates the appropriateness of the model to test the alternate hypothesis if job satisfaction is positively related to lecturers' performance within theological college in West Java, Indonesia. The strength of association of job satisfaction $\left(\mathrm{X}_{3}\right)$ to lecturers' performance $(\mathrm{Y})$ is observable from coefficient correlation $\left(\mathrm{rx}_{3}\right)=0.609$.

Tabel 3. Linearity test and coefficient of correlation of job satisfaction $\left(X_{3}\right)$ to lecturers' performance $(Y)$

\begin{tabular}{|c|c|c|c|c|c|}
\hline Observation & $\mathbf{R}$ & $\mathbf{R}^{\mathbf{2}}$ & $\mathbf{F}_{\text {-test }}$ & $\mathbf{F}_{\text {-tabel }} \alpha$ & Conclusion \\
\cline { 1 - 4 } $\mathbf{n}$ & $\mathbf{R x}_{\mathbf{3}}$ & $\mathrm{r}^{2} \mathrm{x}_{3}$ & $\mathbf{F x}_{\mathbf{3}}$ & 0.05 & \\
\hline 84 & 0.609 & 0.371 & 1.313 & 1.770 & Linear \\
\cline { 1 - 3 }
\end{tabular}

The table shows that $F_{\text {test }}=1.313$ is below critical value where $F_{\text {-tabel }}$ for $(\alpha=0.05)$ is 1.770 indicating that the data is linear and eligible for the next process. Coefficient of correlation $\left(\mathrm{r}_{\mathrm{x} 2}\right)=0.609$ indicates a moderate positive relationship between job satisfaction and lecturers' performance. Coefficient of determination $\left(\mathrm{r}_{\mathrm{x} 3}^{2}\right)=0.371$ indicates that contribution of job satisfaction to lecturers' performance is $37.1 \%$ while the rest $62.9 \%$ is determined by other factors not included in the model.

The findings obtained from this study indicate if the lecturers were very satisfied with their work and experience positive emotions at work, they can do their jobs better and chose to remain with the company for a long period of time. This is in line with the theory put forward by Colquitt, Lepine, and Wesson (2009) who defined job satisfaction as a pleasant emotional state resulting from the assessment of job or work experience. Thus job satisfaction will improve lecturer's performance so that the impact is improving the effectiveness of organizational functions. This way the results of this study further support the results of previous studies about the positive influence of job satisfaction on the lecturers' performance. Similarly, based on the analysis of the results of qualitative research through observation, interviews, focus group discussions and document review, it is known that there is significant effect of job satisfaction to lecturer's performance. This reinforces the results of quantitative research which significantly proves the third hypothesis of this study that there is a positive relationship between job satisfaction with the performance.

\subsection{Organizational Culture, Emotional Intelligence and Job Satisfaction to Lecturers' Performance}

When tested together the model is specified as:

$\hat{Y}=b_{0}+b_{1} X_{1}+b_{2} X_{2}+b_{3} X_{3}+e$

Where:

$\hat{\mathrm{Y}}=$ Lecturers' Performance

$\mathrm{b}_{0}=$ Constant

$\mathrm{b}_{1}, \mathrm{~b}_{2}, \mathrm{~b}_{3}=$ regression coeficient

$\mathrm{X}_{1}=$ Organizational Culture

$\mathrm{X}_{2}=$ Emotional Intelligence

$\mathrm{X}_{3}=$ Job Satisfaction

$\mathrm{e}=$ error 
Relationship between Organizational Culture, Emotional Intelligence and Job Satisfaction to Lecturers' Performance

Tabel 4. Multiple Regression Analysis Summary

\begin{tabular}{|c|c|c|c|c|c|c|c|}
\hline Model & $\beta$ & $\mathbf{R}$ & $\mathbf{R}^{\mathbf{2}}$ & $\mathbf{F}_{\text {-test }}$ & $\mathbf{F}_{\text {-tabel }} \alpha$ & Conclusion \\
\hline & & & & & \multicolumn{2}{|c|}{$\mathbf{0 . 0 5}$} & \\
\cline { 1 - 5 } \cline { 5 - 8 } & & & & 23.920 & \multicolumn{2}{|c|}{2.720} & Significant \\
\hline Organizational Culture & 0.13 & & & & & & \\
\hline Emotional Intelligence & 0.36 & 0.688 & 0.473 & & & & \\
\hline Job Satisfaction & 0.30 & & & & & & \\
\hline
\end{tabular}

Tables 4 show the results of multiple regression analysis deriving the following equation: $\hat{Y}=34.29+$ $0.13 \mathrm{X}_{1}+0.36 \mathrm{X}_{2}+0.30 \mathrm{X}_{3}$. The table reports a significant $\mathrm{F}$ statistic, indicating that the model has strong prediction strength $(F=23.920, p<0.05)$. As further shown in Table 4, all variables altogether are correlated to lecturers' performance as shown by coefficient of correlation $=0.688$ and $47.3 \%$ of the variation in determination of lecturers' performance is explained by the model ( $\mathrm{R}$ Square $=0.473$ ), while other $52.3 \%$ is determined by other factors.

The findings in this study indicate that, if lecturers in performing duties and functions are able to create, adapt, develop and implement the organizational culture within themselves as well as in its organizational and capable of managing emotional intelligence well and proportionately and together having a strong desire, momentum and enthusiastic in carrying out duties for having controlled emotions, and lecturers who are satisfied with their work and experience positive emotions at work, they can do their jobs better and chose to remain with the organization for a long period of time,

Other $52.3 \%$ factors contributing to performance based on the observation, interviews and documentation in the field of qualitative research are: 1) Leadership displayed by the Chairman of Theological College, 2) Motivation of lecturers and 3) Personality.

\section{Conclusion}

Based on the results of hypothesis testing and discussion of research it is found out that:

1. There is a positive significant relationship between organizational culture to lecturers' performance, meaning that the stronger the organizational culture the higher the lecturers' performance.

2. There is a positive significant relationship between emotional intelligence to lecturers' performance, meaning that the higher emotional intelligence the higher the performance of lecturers.

3. There is a positive significant relationship between job satisfaction to lecturers' performance, meaning that the higher the job satisfaction, the higher the performance of lecturers.

4. There is a positive significant relationship between organizational culture, emotional intelligence and job satisfaction altogether to lecturers' performance, which means that the stronger the organizational culture, the emotional intelligence and the job satisfaction overall, the better the performance of lecturers.

\section{REFERENCES}

Colquitt, J., Lepine, J. A., \& Wesson, M. J., Organizational behavior: Improving performance and commitment in the workplace. McGraw-Hill/Irwin, 2009, ch.2 pp. 66-70.

Covey, F., \& Covey, S. R. (2005). The 7 Habits of Highly Effective People: Signature Program: Achieving Personal and Interpersonal Effectiveness from the Inside Out. Franklin Covey.

Gibson, J.L., John M. Ivancevich, James H. Donelly Jr, \& Robert Konopaske. Organizational: Behavior, Structure, Processes, 2012, New York: Mc Graw-Hill. pp. 344-345.

Ivancevich, G., \& Konopaske, D. (2006). Organizations, Behavior. Structure, Process.

Kramadibrata, E. S. (2010). Kinerja Sumber Daya Manusia Perbankan Analisis Pengaruh Persepsi Karyawan tentang Budaya Organisasi, Etos Kerja, Pendidikan dan Pelatihan terhadap Kinerja Karyawan Bank Jabar(Doctoral dissertation, Universitas Pendidikan Indonesia).

Luthans, F. (2012). Psychological capital: Implications for HRD, retrospective analysis, and future directions. Human Resource Development Quarterly, 23(1), 1-8.

Rue, Leslie W. and Lioyd L Byars. "Supervision Key Link to Productivity”. New York: Mc Graw Hill, 2007, pp.123.

Zeidner, M., Matthews, G.,\& Roberts, R.D.(2009). What we know about emotional intelligence. London: A Bradford Book, 441. 